\title{
Stillborn: Regulated Midwifery in Nova Scotia
}

\begin{abstract}
The purpose of this article is to investigate why midwifery policy has failed in Nova Scotia in spite of its success elsewhere in Canada. The primary method of investigation will be to analyse the policy and its implementation through Paul Sabatier and Daniel Mazmanian's framework for policy implementation analysis. The subsequent examination will make clear that the failure of regulated midwifery in Nova Scotia is due to poor implementation, and in particular, the statutory factors that affect implementation. Despite more recent government announcements, regulated, accessible, and effective midwifery care for Nova Scotians remains an unrealized policy creation that lacks government support.
\end{abstract}

\begin{abstract}
About the Author: Brett Taylor is currently pursuing a combined Master of Public Administration and Law degree at Dalhousie University. Prior to attending Dal he earned a B.A. and M.A. in history from McMaster University. His submission on the implementation of midwifery in Nova Scotia was originally written for a first year policy course, PUAD 5120, in the MPA program. Though Brett grew up in Beamsville, Ontario he also lived in Hamilton, Ottawa, Montréal, and Vienna before settling outside of Halifax in beautiful Shad Bay.
\end{abstract}




\section{Introduction}

On March 18 2009, Nova Scotia became the seventh Canadian jurisdiction to regulate midwifery ${ }^{1}$, publicly funding and legalizing a profession that had existed outside the structures of the formal health care system since 1985 (Born, 2003). While midwifery is thriving in Ontario, British Columbia, and Manitoba, it has stagnated in Nova Scotia. An independent report to the government released in August 2011 concluded that if left in its present state the profession would collapse and the benefits of midwifery would fail to be realized in Nova Scotia (Kaufman, Robinson, Buhler, \& Hazlit, 2011).

The purpose of this article is to investigate why midwifery policy has failed in Nova Scotia in spite of its success elsewhere. The primary method of investigation will be to analyse the policy and its implementation through Paul Sabatier and Daniel Mazmanian's framework for policy implementation analysis. The subsequent examination will make clear that the failure of regulated midwifery in Nova Scotia is due to poor implementation, and in particular, the statutory factors that affect implementation. Before analysing the consequences of Nova Scotia's midwifery policy over the past two years, this article will present a brief history of midwifery in Canada and an overview of its implementation in other jurisdictions. This will provide the background for the analysis of the Nova Scotia experience.

\section{Midwifery in Canada}

In 1895 the Canadian Parliament, under pressure from physicians, formally excluded midwifery from legal heath care in Canada and made birth the exclusive domain of physicians (Born, 2003). High maternal mortality was blamed on midwives and was used as support for making the hospital the primary delivery location (MacDonald, 2006). Until this exclusion midwifery had been practiced as a lay profession with no formal training other than experiential apprenticeships. Attempts to reinstate midwifery as a branch of nursing similar to nursemidwifery in the United States were met with little success (Bourgeault, 2000). The Canadian Medical Association, as well as provincial colleges of physicians and surgeons, opposed midwifery on the contention that it was an inferior standard of care. Nursing associations opposed it as an encroachment into their area of care (Born, 2003). Until the 1970s, midwifery persisted almost exclusively in northern or frontier regions where it was allowed to continue primarily due to a lack of other options (Born, 2003). In the 1970s, though still unregulated and outside the health care system and legal structures, midwifery made a small resurgence in a backlash against the medicalization of childbirth (Bourgeault, 2000).

\footnotetext{
${ }^{1}$ Midwifery is currently regulated in Ontario (1993), British Columbia (1998), Alberta (1998), Quebec (1999), Manitoba (2000), the North West Territories (2005), and Nova Scotia (2009). In each of these provinces except Alberta it is fully publicly funded.
} 
From this resurgence, midwifery evolved again into a lay profession which was based upon an experiential and informal learning process. Though a number of commissions investigated incorporating midwifery into mainstream medicine, it has been suggested that these were politically motivated moves that aimed to garner the support of women's groups and feminists, rather than sincere examinations. Further, as an unregulated legal delivery mode, some midwives were criminally charged for practicing medicine without a licence or negligence leading to death (Bourgeault, 2000). In response, midwives began to organize politically and lobby for integration and regulation.

The death of an Ontario baby in 1985 brought the situation into the public eye and prompted the move to regulation and integration (Born, 2003). On January 1, 1994 midwifery was established as a self-regulating, autonomous profession in Ontario (Paterson, 2011). On January 28, 1994 two midwives delivered a baby at the Markham-Stouffville Hospital, with no doctors present, for the first time in Canada (Campion-Smith, 1994). As a part of the regulatory process, Ontario established a four year university program which combines placements and experiential learning with theoretical medical learning to train new midwives and legitimize the profession (Paterson, 2011). Since then, midwifery has been regulated in five other provinces and the North West Territories and has been generally successful in all regions.

\section{Midwifery in Nova Scotia}

Nova Scotia is the most recent Canadian jurisdiction to regulate midwifery. Unlike most other jurisdictions that followed Ontario's lead, Nova Scotia has not adopted the Ontarian model. Instead of rolling out midwifery across the entire province, Nova Scotia has created three model sites to begin delivering regulated midwifery care to Nova Scotians (Bourgeault, 2000). The Department of Health and Wellness received and accepted three proposals for implementing midwifery service. Seven positions were created in the province; three at the Izaak Walton Killam Hospital (IWK), two in the South Shore District Health Authority (SSDHA) and two in Guysborough Antigonish Strait Health Authority (GASHA) (Kaufman et al., 2011, 5). In all locations, midwives receive a salary, benefits, and are insured.

In November 2010, the Nova Scotia Department of Health and Reproductive Care commissioned Implementation of Midwifery in Nova Scotia, a report on the implementation to date (Research Power, 2010). Concerned by the observations and recommendations of that report and by the cessation of midwifery services at the IWK, in December 2010 the government commissioned an additional external report, which was released in August 2011. Both reports indicated significant implementation problems and noted that considerable action was needed from the government to support the continued implementation of midwifery in the province.

This article will use the reports' findings in order to advance its argument of implementation failure. The aim of this article, however, is not to reproduce the findings of the report which 
detail the specific areas where improvement is needed. Rather, this article will investigate the structural causes of implementation failure, through the use of an analysis framework for evaluating implementation.

\section{Sabatier and Mazmanian's Implementation Framework}

Paul Sabatier and Daniel Mazmanian have proposed an analytical framework for examining policy implementation. For the purpose of this article, I will accept its tenets and use it to evaluate the implementation of midwifery in Nova Scotia. Sabatier and Mazmanian classify the factors impacting implementation in three broad categories; the tractability of the problem, statutory factors, and non-statutory factors.

In evaluating the implementation of Nova Scotia's midwifery policy this article will sequentially explore each of these factors. Through this exploration, it will be argued that while all three were in some way responsible for the midwifery implementation failure, the statutory factors played a more significant role. The 2009 regulation was reactive, not proactive, and was not designed with implementation in mind. The statutory shortcomings of this policy have crippled its success.

\section{Tractability of the Problem(s)}

Sabatier and Mazmanian (1981) define the tractability of a problem as "the specific aspects of a social problem that affect the ability of governmental institutions to achieve statutory objectives..." (6). While these obviously impact the effective implementation of a policy ${ }^{2}$, this article contends that they are not responsible for the failure of midwifery in Nova Scotia. Five other Canadian jurisdictions have successfully integrated midwifery into their health care provisions. While Nova Scotia is indeed a unique province, its specific differences alone are not enough to account for the failure of the service. The specific factors affecting tractability and the degree to which they affect the implementation of midwifery follow.

\section{Difficulties in Handling Change}

Sabatier and Mazmanian (1981) claim that to successfully modify the behaviour of a target group, it is necessary to clearly identify the problem and supply a valid causal theory to support the proposed behavioural alteration. Within the policy and legislation of Nova Scotia no clear problem is defined. A variety of problems could be inferred or proposed.

- Inaccessibility of midwifery care in Nova Scotia

\footnotetext{
${ }^{2}$ When this article refers to Nova Scotia's midwifery policy, it is referring not only to Bill 107 , which legalized and regulated the profession, but also to the policies undertaken by the government over the past two years to implement midwifery service delivery. That is, the hiring of the seven midwives at IWK and in the two DHAs.
} 
- The existence of a parallel health service being offered outside legal structures and provincial health funding.

- The risks to citizens inherent in unmonitored and unregulated provision of maternity care.

The fact that no problem is clearly identified makes evaluating implementation and policy success difficult. If the problem is defined as inaccessibility, for example, the implementation is a dismal failure as midwifery is now only available in select locations. However, if the problem is defined as regulating a health practice that was previously extra-legal, the program has been a resounding success - midwives are now regulated.

In evaluation of Ontario's implementation and regulation it has been argued that the problem was defined as protecting women from incompetent midwives (Paterson, 2011). With regulation, and training this problem was addressed, while also respecting the tenets of midwifery and bringing the profession into the Ontario health care system.

For the purpose of this article, the problem will be identified as bringing Nova Scotia in line with the primary health care provided by other provinces. This is consistent with the policy statement provided on the Department of Health and Wellness website (2011) "Midwifery is being introduced gradually into Nova Scotia". This arguably is the closest reference to a goal or vision statement. If the goal is the introduction of midwifery, it is reasonable to infer that the problem was that it was not previously available and that Nova Scotia was lagging behind other Canadian jurisdictions.

Further, if this is the problem, there is a valid causal link between the behaviour being regulated and the identified problem. Regulation that includes midwives and provides a forum for physicians, and other health care professionals to work with them, to resolve the problem of an absence of - or inadequate access to - midwifery as a health care option. Leaving aside the failure of the Nova Scotian government to define its problem, this approach should pose little impediment to implementation.

\section{Diversity of Proscribed Behaviour}

Sabatier and Mazmanian (1981) claim there is a link between the variety of behaviors being regulated and the difficulty in implementation: "The more diverse the behavior being regulated, the more difficult it becomes to frame clear regulations and thus the less likely that statutory objectives will be attained" (8). Midwifery, as will be explained below, encompasses an incredibly wide variety of activities.

Midwifery, while it encompasses a wide variety of behaviours, is governed by a regulatory body that maintains professional standards and a code of ethics (Midwifery Regulatory Council of Nova Scotia [MRCNS], 2011b). In this way, regulation should be straightforward. 
Nevertheless, the behaviours of other stakeholders may need to be altered in order to implement midwifery seamlessly and successfully as a part of the health care system. Doctors, nurses, hospital staff, and administration all have to be convinced that accepting midwifery is a step forward. Further, in each of the three model sites, beliefs, behaviour, and organizational structure may differ. In essence, there can be an enormous diversity of behaviours to regulate. This, in fact, was noted as an obstacle by the 2010 report on implementation (Research Power, 2010). This difficulty was exacerbated by the province in divesting authority to each of the three model sites and allowing three distinct models to emerge.

\section{Percentage of Population Whose Behaviour Needs to Be Changed}

Sabatier and Mazmanian (1981) hold that the smaller the group whose behaviour requires change, the easier it will be both to motivate political support for change and to enact or enforce that change. In Nova Scotia, the percentage of the population required to change doctors, nurses, hospital staff, and administration - is relatively small. However, when viewed as a proportion of primary maternity caregivers, this population is a mainstream majority. On the other hand, the seven midwives form a tiny fringe of Nova Scotia's primary maternity caregivers. In addition, regulation requires behavioural change in all stakeholders. Midwives will need to change to accommodate integration within the system just as the existing actors will be required to change to integrate midwives. Unfortunately, skewed perspectives have been nurtured as a result of both groups working in isolation. In sum, regulation requires behavioural change within the entirety of the effected population.

\section{Extent of Behavioural Change Required of Target Groups}

Sabatier and Mazmanian (1981) propose that it is not only the size of the target group, but the amount of change required of this group, that affects implementation. The larger the change required, the more difficult implementation will become.

In Nova Scotia, the change required for doctors and nurses can be seen as either large or small. In one respect it is small - letting someone else make deliveries - is as simple as absenting. This is particularly the case if midwives deliver outside of the hospital at a client's home - there need not be any interaction with the health care professionals they are replacing. While this has implications for losing scope of practice, it is a relatively easy change to make.

Alternatively, however, the change required can be immense. When a midwife delivers within the hospital, interactions with nurses, hospital staff, and administration are essential. In the case of a consultation or transfer of care, physicians by necessity must interact with midwives. ${ }^{3}$ This forced acceptance of a new profession is a large behavioural change especially given the

\footnotetext{
${ }^{3}$ That this tends to be a primary interaction can also serve to undermine confidence in midwives as the physician's observance of the profession is limited to the cases that develop poorly.
} 
potential significant differences that underpin their respective professions' philosophy on care delivery.

\section{Tractability as a Cause of Implementation Failure in Nova Scotia}

This article argues that the tractability of the problem is not sufficient cause for the implementation failure witnessed in Nova Scotia's midwifery policy between 2009 and 2011. As stated by Sabatier and Masmanian (1981) "one should be cautious about placing too much emphasis on the tractability of the problem" (9) as many difficult problems have been effectively tackled. Furthermore, they state the purpose of their framework is to show how even complex problems can be addressed with a better understanding of how statutory and political variables affect implementation (Sabatier \& Mazmanian, 1981, 9). In the case of midwifery, the nature of the problem, no matter how complex, cannot fully be the cause of failure. Midwifery has been successfully implemented elsewhere in Canada where similar opposition was encountered.

\section{Extent to which the Statute Coherently Structures Implementation}

The statute proper did not enable or structure the implementation process in any way (Government of Nova Scotia, 2006). The legislation which regulated midwifery merely created the legal structures enabling regulation, specifically the creation of the Midwifery Regulatory Council of Nova Scotia (MRCNS). Beyond this, however, the implementation process and policy proceeded ad hoc and was not structured or provided for by the statute. This paper proposes that this is the main cause of the implementation failure in Nova Scotia. As the many statutory factors are examined it will become clear not only that Nova Scotia's policy failed to provide sound structure to implement the policy, but that doing so could have positively affected the implementation process.

\section{Precision and Clear Ranking of Statutory Objectives}

"Statutory objectives that are precise and clearly ranked in importance serve as an indispensable aid in program evaluation, as unambiguous directives to implementing officials, and as a resource available to supporters of those objectives" (Sabatier \& Mazmanian, 1981, 10). As mentioned earlier, midwifery policy in Nova Scotia has no clear objectives or goals (Government of Nova Scotia, 2006, 2011). Without clear objectives it is easy for a program to fail.

Objectives can serve as resource to those affected who perceive that outputs are not in line with objectives (Sabatier and Mazmanian, 1981,10). As opposed to the Nova Scotia Government's Midwifery policy, it is notable that the MRCNS does have specific objectives which relate to care delivery (MRCNS, 2011c). It is also important to note that due to the 
current structure of implementation, some of these objectives are not being met. ${ }^{4}$ It is understandable that with regulation, midwives would expect the policy goals to be in line with their care delivery goals and this lack of support and consistency as well as the inability to meet their own objectives would be a source of frustration. The 2010 report recommended that the government should clearly define key midwifery terms which are integral to the implementation of the "Canadian Model of Midwifery" (Research Power, 2010, 40).

Sabarier and Mazmanian further note that if implementation is going to be delegated to an existing agency the statute should clearly indicate the priority of the new directive within the totality of the agency's operation. Failure to do so will result in the new directive being given low priority and not being implemented quickly or with force (Sabatier \& Mazmanian, 1981, 10). While Nova Scotia delegated the incorporation of midwifery to the IWK and two DHAs, it gave no direction, publicly at least, on the importance of integration of the new service.

\section{Validity of the Causal Theory Incorporated into the Statute}

Sabatier and Mazmanian (1981) argue that policy success is dependent upon the "causal linkages between government intervention and the attainment of program objectives" being fully understood and explained within the policy (11). Further, they maintain, that it is imperative for the implementing agency and/or officials to have jurisdiction over the areas required to achieve these policy objectives.

In Nova Scotia, midwifery legislation makes no mention of a causal link (Government of Nova Scotia, 2006). The Midwifery Regulatory Council, however, makes the link between regulation and insurance of safe care on its website (MRCNS, 2011a). While this addresses the mission of the MRCNS, it does not address the policy goal, as defined by this article, of delivering midwifery service to Nova Scotians or a causal link between the actions of the government and achieving this output.

Additionally, the MRCNS is not the implementing agency. The implementing agencies in Nova Scotia are the Department of Health and Wellness (DHW), the IWK, and the two DHAs. While the DHW does have jurisdiction over the areas required to achieve the output, it has not exercised it except for the provision of funding and delegation of authority. Implementation and integration was left to the IWK and the DHAs with funding from the DHW.

\footnotetext{
${ }^{4}$ Current staffing prevents home births being an option in Halifax. Staffing limitations in the two DHAs also prevent midwives from being able to effectively offer continuity of care if calls come in at the same time. This was cause for the 2011 report to recommend hiring more midwives in each district (Kaufman et al., 15-16). Understaffing resulting in an inability to provide homebirths was also noted by the 2010 report (Research Power, 2010, 25).
} 


\section{Financial Resources Available to the Implementing Agency}

Sabatier and Mazmanian's (1981) framework holds that a minimum level of funding is required "for there to be any possibility of achieving statutory objectives" (11). Funding for midwifery has been set by the province through the DHW rather than through the implementing agencies on the front line - the IWK and the two DHAs. In essence, the implementing agencies were left with no financial resources to pursue the policy goals and ensure policy outputs were realized.

Both review studies indicated that understaffing was a key factor in stifling the progress of implementation. Accordingly, the two studies recommended further increases in funding for staffing for both more midwives and more support staff (Research Power, 2010, 42; Kaufman et al., 2011, 13, 15). Without the financial resources to respond locally to demand, the DHAs and the IWK are bound by the financial decisions of the DHW. In essence, the implementing agencies have not been granted the financial resources necessary to ensure successful implementation.

\section{Hierarchical Integration within and among Implementing Institutions}

Sabatier and Mazmanian identify the structure of implementing institutions relative to each other as an important factor in achieving success. Specifically, "one of the principal obstacles [in policy implementation] is the difficulty of obtaining coordinated action within any given agency and among the numerous semiautonomous agencies involved in most implementation efforts" (Sabatier \& Mazmanian, 1981, 12). They note that this is more acute when delivery responsibility is delegated to local agencies in systems that have large local variations. Variation, if not controlled by standards within the statute, will lead to "considerable variation" in compliance both with implementing officials and the target groups (Sabatier \& Mazmanian, 1981).

Nova Scotia specifically allowed the three model sites to develop their own practices and procedures. The result has been three systems which "are very different in the approach they have taken to integrating midwives into the system" (Research Power, 2010, 39). The largest disparity being that while at IWK the midwives are employed by the hospital, however, in the two DHAs (where they are employed by the DHA instead of the hospital), there have been differences in and difficulties with midwives getting privileges at hospitals (Kaufman et al., $2011,14)$.

\section{Extent to Which Decision-Rules Support of Statutory Objectives}

Sabatier and Mazmanian hold that the decision making process must include decision makers within the ruling body overseeing implementation. Of primary importance is whether or not decision makers are likely to make rulings that support or are consistent with the policy's objectives (Sabatier \& Mazmanian, 1981). In essence, does the design of implementation bodies give them the power needed to support policy objectives? 
In Nova Scotia, the MRCNS was set up as a regulatory body to register midwives and oversee their scope of practice, but was not endowed with adjudication powers. The DHAs and IWK would be the most likely agencies to mediate disputes during implementation. As bodies that had formerly existed without midwifery and in opposition to it, one might assume that these agencies would have considerable difficulty providing a balanced and neutral mediation. Such may well have been the case as demonstrated in 2010 at the IWK model site when two midwives were fired and a third resigned in protest (CBC, 2010). This move not only ceased midwifery care at the IWK for more than six months, but changed the course of care being delivered to sixty women who had been under the midwives care (Côté, 2011). While there were no such public conflicts in the DHA model sites, both reports did note administrative tensions and the complexities of inter-professional cooperation.

\section{Assignment to Agencies/Officials Committed to Statutory Objectives}

"No matter how well a statute structures the formal decision process, the attainment of statutory objectives that seek to significantly modify target-group behavior is unlikely unless officials in the implementing agencies are strongly committed to the achievement of those objectives" (Sabatier \& Mazmanian, 13). Insomuch as the implementing agencies - the two DHAs and the IWK - applied to become model sites, one may infer from this that they support the implementation of midwifery. The degree of this support, particularly relative to other agency priorities, is questionable.

Further, Sabatier and Mazmanian (1981) assert that successful implementation requires not just passive support but persistent vociferous support, without which recalcitrant officials or stakeholders cannot be overcome. They suggest that implementation be assigned either to agencies whose policy orientation is consistent with the statute or to an agency whose traditional mandate is compatible with the new direction. Insofar as the IWK and DHAs are motivated to deliver first class health care, their orientation and mandate can be seen as compatible with the goals of midwifery regulation. It is notable, however, that these institutions, and the medical professions generally have traditionally regarded midwifery as an inferior health care mode and not compatible with their delivery of first class care. In 2008, just months before regulation, the IWK sanctioned a midwife for interference in a hospital birth (CBC, 2008). While this view can be overcome, assigning implementation to agencies that have traditionally been in conflict with midwifery has not aided its successful implementation.

An additional factor that can aid implementation, in addition to or in spite of the above mentioned factors, is the selection of top implementing officials from the population benefiting from or supporting the policy's objectives (Sabatier \& Mazmanian, 1981). In Nova Scotia, this could have been achieved by including a representative from the Midwifery Coalition of Nova Scotia, the midwifery advocacy group that had been most involved in pushing for regulation, and a 'consumer' group representing women who support midwifery care. This representative could have been involved directly at the provincial level or a representative could have been 
selected locally in each of the sites. This could have been a paid or volunteer position and integrated into the implementation in any number of ways. This, however, was not done and the Midwifery Coalition of Nova Scotia continues to advocate for better and more effective implementation from an outside and adversarial position.

\section{Biased Participation Opportunities for External Actors}

Sabatier and Mazmanian (1981) assert that implementation is effected by the extent to which legal or other structures favour participation of those actors supportive of a policy's objectives. They note that typically the groups targeted by regulation do not have problems with legal standing or lack the financial resources to make use of the legal system to their benefit. Potential benefactors, on the other hand, tend to be disaggregated and as individuals lack similar legal standing or financial resources. As such, they are less likely to appeal to the legal system in order to ensure a policy's continued implementation and policy objectives are met (Sabatier \& Mazmanian, 1981).

In Nova Scotia the target groups whose behaviour is being modified are the IWK and the DHAs, as well as nurses, doctors, and other stakeholders within the health care system. These groups are well established, have legal standing in the province, and have professional bodies which advocate to their advantage. Benefactors are both midwives, who have gained professional recognition, and that segment of the public interested in attaining midwifery care.

Midwifes are a newly minted profession with legal standing. They are incredibly weak, however, when compared with their nurse and physician counterparts. Midwives have been regulated for just two years, there are only five (initially 7 ) of them in the province, and their association has little experience or administrative might. The MRCNS has only one part time employee and is a regulatory body as opposed to a political advocacy group or a professional association (Kaufman et al., 2011).

The benefactors in the public - pregnant women wanting alternative care - are a disaggregated group who fit the model of individuals with few resources described by Sabatier and Mazmanian. It is important to note that in addition to this, the benefactors are women who historically have been disadvantaged in terms of political and economic power. Further, they are a subset of the female population at large; women of childbearing age interested in care options outside the institutional status quo.

In sum, in Nova Scotia the opportunities for participation by external actors are biased towards those representing the status quo. Actors likely to support the statutory objectives are comparatively disadvantaged and less likely to make recourse to the legal or political system in support of implementation. 


\section{The effect of Statutory Variables in Nova Scotia}

Through use of Sabatier and Mazmanian's framework it has become clear that statutory variables greatly affected the implementation of midwifery policy in Nova Scotia. Nova Scotia's policy and legislation does not adequately provide for or protect the implementation process. In fact, the implementation of midwifery in Nova Scotia can best be described as ad hoc and haphazard. While flexibility is desirable to promote responsiveness to local variation and changing conditions, it denies the policy the protection midwifery initially needs in order to survive. Nova Scotia's management of statutory factors affecting policy implementation displayed little foresight and a lack of political or institutional support for midwifery in Nova Scotia. So severe was this mismanagement that this article contends it outweighs any other factor leading to the implementation failure of midwifery in the province.

\section{Non-statutory Variables Affecting Implementation}

In addition to the statutory factors affecting implementation, Sabatier and Mazmanian identify a number of non-statutory variables that alternately lead to or hinder implementation success. Broadly speaking, these are societal factors which are at times beyond the control of the government or implementing agency. Generally there are two main factors. First,

...the need for any program that seeks to change behaviour to receive constant and/or periodic infusions of political support of it is to overcome the inertia and delay inherent in seeking cooperation and acquiescence among large numbers of people, many of whom perceive their interest to be adversely affected by successful implementation of statutory objectives. (Sabatier \& Mazmanian, 1981, 15)

The second factor is the effect of changing socioeconomic conditions on the availability of support in the public, interest groups, and government (Sabatier \& Mazmanian, 1981).

This article will note that a number of these factors have adversely affected the implementation process. On the other hand, a number of factors ought to have aided implementation. It is maintained that while the non-statutory factors have had some effect, their relative importance in implementation failure pales in comparison to the statutory factors discussed previously.

\section{Variation in Conditions Affecting the Attainability of Statutory Objectives}

Sabatier and Mazmanian propose that variation over time can change the prioritization of policy outputs. Specifically, if other problems emerge as more important, "political support for allocating scarce resources to the original statute is likely to diminish" (Sabatier \& Mazmanian, $1981,16)$. Given that only a brief two years have passed since implementation, this likely has played a negligible role in the implementation failure. 
Of more relevance to midwifery in Nova Scotia is the effect of regional variation. They write:

...successful implementation is rendered more difficult by local variation in socioeconomic conditions and, as indicated previously, in the seriousness of the problem being addressed. Such variation produces enormous pressures for "flexible" regulations and considerable administrative discretion for local units. But such discretion increases the probability of variation in the extent to which the policy outputs of implementing agencies are consistent with statutory objectives. On the other hand, the imposition of uniform standards on jurisdictions with widely different situations almost inevitably increases opposition from those who must bear the costs that appear unjust. In either case, statutory objectives are less likely to be achieved. (Sabatier \& Mazmanian, 1981, 16)

That this is the case in Nova Scotia, seems to have had little effect on the support or opposition of those bearing the costs. There has been no protest from Nova Scotians not benefiting from midwifery for bearing the cost of it. Further, the regional variation and considerable administrative discretion accorded to the three model sites was not a response to economic conditions, but rather a design of the implementation.

The last variation noted by Sabatier and Mazmanian is the economic viability of the target groups. They note that "support for regulation aimed at environmental or consumer protection or worker safety seems to be correlated with the economic viability of target groups and their relative importance in the total economy" (Sabatier \& Mazmanian, 1981, 16). Not only have women historically been a less important economic force, but strictly speaking, pregnant women are the least economically viable segment of society. ${ }^{5}$ While this doubtlessly has had some effect on the political support, it cannot alone account for the spectacular failure of implementation in Nova Scotia.

\section{Media Attention to the Problem Addressed by a Statute}

Sabatier and Mazmanian argue that media attention plays a pivotal role in implementation success. They note that often this role is not helpful as media outlets play an issue to its extreme and then quickly move on and lose attention. This is an obstacle to the continued political support necessary for most protection programs to succeed (Sabatier \& Mazmanian, 1981).

While media attention has fluctuated in Nova Scotia, the continued vulnerability of the profession paired with continual calls from the public for extended or more comprehensive

\footnotetext{
${ }^{5}$ This should not be read as pejorative or inflammatory, but one of the reasons women have been seen as less important economically is their periodic absence from the labour force for the purpose of bearing children. So by extension the subset of women who are pregnant would be seen as even less economically important. A pregnant woman, or woman on maternity leave is not only not contributing to the economy but may even be seen to be acting as a drain on it.
} 
service has ensured a relatively stable supply of coverage. The implementation report released in November 2010 renewed media attention. The cessation of midwifery services at the IWK in December 2010 and the controversy surrounding it also created a media outburst. There was less media coverage of the resumption of services at IWK in the summer of 2011. But in August 2011 there was a media outburst with the release of the external report that predicted the collapse of midwifery. In short, media attention and its continuity has been a relatively small hindrance to the accumulation of political support in Nova Scotia.

\section{Variations in Public Support for Statutory Objectives}

Sabatier and Mazmanian (1981) have argued that variation in public opinion over time and between jurisdictions make continued public support difficult to sustain. Support for midwifery in Nova Scotia has been consistent. Both reports showed that the support was there and that demand for services far exceeds institutional supply (Research Power, 2010, 25; Kaufman et al., 2011, 12). Regional differences in support were also not seen in either report and this paper would argue that if regional differences were observed, it would be a result of the asymmetrical implementation within the three model sites. In short, it would be the result of statutory factors.

\section{Changes in Resources and Attitudes toward Statutory Objectives}

Sabatier and Mazmanian assert that over time support tends to decrease, with regulation most often occurring as a result of heightened public concern with an issue. This will wane both as a function of decreased media attention, immediacy, and also as a function of the perception that objectives are being/have been met and also as a function of costs associated with implementation being realized (Sabatier \& Mazmanian, 1981, 17-18). Further, because opponents are more able to intervene over time than proponents, there is a tendency for regulation to be watered down with time.

This process has been seen in Nova Scotia. The current availability of midwifes(ves?) is lower than at the outset of regulation and understaffing prevents full scope care including home births. ${ }^{6}$ This has not been the result of opposition intervention as suggested by Sabatier and Mazmanian, however, but is a result of poor program design.

\section{Continued Support for Statutory Objectives in Implementing Institutions}

Sabatier and Mazmanian (1981) have identified that in cases where there are multiple bodies or agencies involved in implementation, they tend to be deferent to their most significant income source. In this case, it is important to note that the MRCNS has zero financial influence

\footnotetext{
${ }^{6}$ Though midwifery has resumed at the IWK the one midwife practicing there brings the provincial total to five, down two from the seven at regulation. The sole midwife in Halifax is unable to provide home births due to understaffing.
} 
on either the IWK or the DHAs. Thus local administrative decisions are more likely to favour the goals of the DHAs and IWK ahead of the MRCNS or the midwives. While respective goals will often be similar, they will at times differ.

Sabatier and Mazmanian (1981) note this pressure can be alleviated through formal oversight or formal changes to funding structures to promote implementation. They also note that promotion of policy goals can be effectively achieved through use of a fixer, "an important legislator or executive official who controls resources important to crucial actors and who has the desire and the staff resources to closely monitor the implementation process and to intervene on an almost continual basis" (Sabatier \& Mazmanian, 1981, 19). Neither formal oversight nor a financial reorganization of funding was pursued in Nova Scotia. There also wasn't a fixer in the government to push through implementation and ensure outputs were realized.

\section{Commitment and Leadership Skill of Supportive Implementing Officials}

"The variable most directly affecting the policy outputs of implementing agencies", Sabatier and Mazmanian (1981) argue, is the support of relevant officials measured by their commitment "to the realization of statutory objectives" (19-20). In Nova Scotia these officials could be regarded alternately as those in the IWK, the DHAs, the DHW, or in the government of Nova Scotia. While the program has met with some successes, more so in the DHAs than at the IWK and specifically in the South Shore, there has been some commitment from officials for the realization of policy goals.

On the other hand, the commitment of government to the overall policy is questionable. When faced with strong recommendations in the November 2010 report, which cautioned that significant changes were necessary, particularly in increased staffing, the government made no changes. After the collapse of midwifery at the IWK in December 2010, the government's response was to commission a second report. After delivery in August 2011, the government implemented none of its recommendations. Support for midwifery from implementing officials is at least somewhat apparent at the lower levels, but at the provincial level there has been little political or operational support for the implementation of midwifery beyond its original introduction.

\section{Effect of the Non-statutory Factors on the Implementation Process}

The effects of non-statutory factors on the implementation process, as identified by the framework of Sabatier and Mazmanian, are certainly not negligible. Of particular note are the relative economic importance of women and the absence of strong official commitment. On the other hand, continued media attention and relatively stable political support ought to have promoted implementation. While these factors are notable, this article asserts they are of less relative importance than the crippling statutory factors which disabled the policy from the start. 


\section{Conclusions and Update}

The implementation of midwifery services in Nova Scotia has, to date, been met with muted success. This article has applied Sabatier and Mazmanian's analysis framework for implementation to investigate the sources of this failure. This analysis has shown that the primary causes of failure in Nova Scotia were statutory factors. Regulation was not executed in a planned fashion, which clearly outlined implementation policies or promoted successful implementation through statutory support. Tractability and non-statutory factors also impeded implementation but had comparatively minor effects on the successful realization of policy outputs.

Since the original writing on this article the Nova Scotia Government announced changes to its midwifery policy. On December 6,2011 , the province committed to undertake the following actions (Government of Nova Scotia, 2011b);

- Hire a midwifery practice specialist to address clinical, organization and operational challenges at model sites and to fully integrate midwifery into the primary maternity care model.

- Create a second attendant program at all three sites to ensure consistent care, to increase capacity for home births, and to make midwifery more readily available to women who select it as part of their birth plan.

- Increase the complement of midwives in the IWK/Capital District health authorities by two full-time equivalents to effectively and safely keep up with the growing demand for services and ensure that women receive the right care based on their needs.

These changes were announced in response to the August 2011 report and were intended to create an environment where midwives are enabled "to work to their full scope within a model that provides the best care possible to women and their families" (Government of Nova Scotia, 2011b).

It is hoped that the announced changes will aide implementation and lead to future success in securing the policy output objective of accessible midwifery care. The hiring of a specialist to oversee implementation and integration within the existing health care system would provide administrative and political support to practicing midwives. The second attendant program would allow midwives to practice to their full scope and deliver a cornerstone of midwifery care - home births. Additional hires at IWK would be an expansion that could strengthen the profession both at that site and generally in the province.

More importantly perhaps, the announcement signals government support of implementation a key factor which had previously been lacking. As important as they are, the changes by no 
means ensure successful implementation and achievement of desired outputs. Several of the statutory problems outlined above are not addressed. Significantly, there is no announced plan to expand beyond the three model sites or to standardize practice between them. The new position of practice specialist could serve to correct a number of statutory problems, but only if endowed with sufficient powers over existing administrators and administrative structures.

While this author had hoped the announcement would be the beginning of a positive change for regulated midwifery in Nova Scotia, as of June 2012 all positions remain unfilled and no further announcements have been made. Regulated, accessible, and effective midwifery care for Nova Scotians remains an unrealized policy creation that lacks government support. 


\section{References}

Bourgeault, Ivy Lynn. (2000). Delivering the 'new' Canadian Midwifery, Sociology of Health \& Illness, 22(2), 172-196.

Born, Karen. (2003). Midwifery in Canada. McGill Journal of Medicine, 7(1). Retrieved from: http://www.med.mcgill.ca/mim/issues/v07n01/rev articles/rev articles.htm

Campion-Smith, Bruce. (1994, January 29). Two midwives, baby make history. The Toronto Star. p. A18

CBC News. (2008, December 18). N.S. midwives warned not to practice in hospitals. CBC News Online. Retrieved from:

http://www.cbc.ca/news/canada/nova-scotia/story/2008/12/18/midwives-warned.html

CBC News. (2010, December 19). Halifax midwifery program needs new home. CBC News Online. Retrieved from:

http://www.cbc.ca/news/canada/nova-scotia/story/2010/12/19/ns-centre-wants-iwksuspended-midwifery-program.html

Côté, Mick. (2011, January 20). Midwifery Kerfuffle. The Coast. Retrieved from: Retrieved from:

http://www.thecoast.ca/RealityBites/archives/2011/01/20/midwifery-kerfuffle

Government of Nova Scotia. (2006). Bill No. 107. Retrieved from:

http://nslegislature.ca/legc/PDFs/annual\%20statutes/2006\%20Fall/c018.pdf

Government of Nova Scotia. (2011). Department of Health and Wellness. Retrieved December 4, 2011. Retrieved from:

http://www.gov.ns.ca/health/primaryhealthcare/midwifery.asp

Government of Nova Scotia. (2011, December 6). Province Strengthens Midwifery.Department of Health and Wellness News Releases. Retrieved December 6, 2011. Retrieved from: http://www.gov.ns.ca/news/details.asp?id=20111206003

Kaufman, Karyn, Robinson, Kris, Buhler, Karen, \& Hazlit, Gail. (2011). Midwifery in Nova Scotia: Report of the External Assesment Team. Halifax, NS: Department of Health and Wellness. Retrieved from:

http://www.gov.ns.ca/health/reports/pubs/Midwifery-in-Nova-Scotia-Report.pdf 
MacDonald, Jo-Ann. (2006). Advanced Practice Nursing: Unification Through a Common Identity. Journal of Professional Nursing, 22(3), 172-179. Retrieved from: http://www.sciencedirect.com/science/article/pii/S8755722306000640

Midwifery Regulatory Council of Nova Scotia. (2011a). MRCNS website. Retrieved December 5, 2011. Retrieved from: http://mrcns.ca/index.php/about-midwives/\#midwifery-in-ns

Midwifery Regulatory Council of Nova Scotia. (2011b). Code of Ethics. Retrieved December 5, 2011. Retrieved from:

http://mrcns.ca/index.php/about-midwives/\#midwifery-in-ns

Midwifery Regulatory Council of Nova Scotia. (2011c). Philosophy of Midwifery Care. Retrieved December 5, 2011. Retrieved from: http://mrcns.ca/images/uploads/Philosophy of Care.pdf

Paterson, Stephanie. (2011). Midwives, Women and the State: (De)Constructing Midwives and Pregnant Women in Ontario, Canada. Canadian Journal of Political Science, 44(3), 483505.

Research Power Inc. (2010). Implementation of Midwifery in Nova Scotia. Retrieved from: http://www.gov.ns.ca/health/primaryhealthcare/documents/Evaluation-of-MW-Report.pdf

Sabatier, Paul A., and Mazmanian, Daniel A.. (1981). The Implementation of Public Policy: A Framework of Analysis. In P. Sabatier \& D. Mazmanian (Eds.), Effective Policy Implementation. Toronto, ON: Lexington Books. 